Original Research Paper

\title{
Remediation of Heavy Metals by using Industrial Waste by Products in Acid Mine Drainage
}

\author{
Nuur Hani Mohammed, Mustapha Atta and Wan Zuhairi Wan Yaacub \\ Geology's Programme, National University of Malaysia, Bangi, Selangor, Malaysia
}

\author{
Article history \\ Received: 19-10-2017 \\ Revised: 04-12-2017 \\ Accepted: 16-12-2017 \\ Corresponding Author: \\ Nuur Hani Mohammed \\ Geology's Programme, \\ National University of \\ Malaysia, Bangi, Selangor, \\ Malaysia \\ Email: nuurhani_88@yahoo.com
}

\begin{abstract}
Acid Mine Drainage (AMD) is one of the main important problems being combated today. Laboratory tank experiments were conducted to evaluate the use of industry waste to adsorb and control the mobilization of metals from contaminated acid mine water. The main physical conditions such as $\mathrm{pH}$ and treatment performance are displayed. The solution of acid mine were sampled from the sites and their concentrations of heavy metals were determined. Three types of industrial waste were used as low-cost adsorbent materials in the treatment process which are Ladle Furnace Slag (LFS), Fly Ash (FA) and Biomass Ash (BA). The materials were described by X-Ray Diffraction (XRD), FESEM images and X-Ray Fluorescence (XRF). A comparative study between the removal efficiencies of heavy metals were evaluated. The results showed that about 78 to $99 \%$ removal efficiencies of metals were achieved from FA tank, 88 to $99 \%$ for LFS tank and 86 to $99 \%$ for BA tank. Tank experiment displays huge range of $\mathrm{pH}$ changes from acidity to nearly neutral phases when adsorbent was in contact with AMD. Remediation of AMD by using FA showed $\mathrm{pH}$ changes from $\mathrm{pH} 2.12$ to 7.09 , $\mathrm{pH} 7.3$ for LFS and $\mathrm{pH}$ 6.8 for BA within 50 days of operation. From the removal rate, it is found that FA, LFS and BA have different efficiencies of heavy metal removing. The removal of heavy metals by using FA are more efficient to remove $\mathrm{Fe}, \mathrm{Mn}, \mathrm{Cu}, \mathrm{Ni}$ and $\mathrm{Zn}$. Meanwhile, LFS sample displayed as an effective adsorbent for treat $\mathrm{Pb}$ and $\mathrm{Cd}$ in acid mine drainage. The industrial waste used in this study increased and neutralized the $\mathrm{pH}$ to control AMD and improve water quality.
\end{abstract}

Keywords: Acid Mine Drainage, Industrial Waste, Heavy Metals, Remediation

\section{Introduction}

The problems of environmental, economic, social and geotechnical stability associated with abandoned, historical or active mine sites is a very serious and global concern in the recent times. The past and current mining practices, cause environmental problems that impair ecosystems and human health. The environmental obliteration arising from polluted water from old and active mines in Bukit Besi area, Malaysia. Small interruption due to the variety of causes may arise from physical hazard to pollution of surface water, groundwater flow and soil nearby. Hefa et al. (2009) stated the composition of mine water was controlled together with local hydrology, geochemistry and geology.

Currently, the on-land deposition of heavy metals through the environment is decreasing due to the productivity of mining operations and legal necessity for dissuading of environmental damage from mining activities. Dybowska et al. (2006) stated metals cannot be decayed through chemical or biological processes into environmentally neutral elements. The formation of AMD happen from oxidation process in abandoned mine lands that occur when mineral of sulphide in the waste rock react against air and water to form sulfuric acid. The formation of AMD is a series of biology, geochemical and mineral dissolution processes from mining activity.There are three main steps from the operational phase of a tailings hoarding until the final phase of AMD (Bernard Dold, 2014). The mineral composition influenced by the oxidation process, when sulfides are oxidized by $\mathrm{Fe}(\mathrm{III})$ and the potential of Fe(III) hydroxide layering (Rimstidt et al., 1994). 
When different sulfides are in contact with each other, the electrochemical processes are likely to take place and influence the reactivity of sulfides (Kwong, 1993). The most common sulfide mineral is pyrite $\left(\mathrm{FeS}_{2}\right)$. Oxidation of pyrite takes place in several steps including the formation of the meta-stable secondary products ferrihydrite $\left(5 \mathrm{Fe}_{2} \mathrm{O}_{3} \cdot 9 \mathrm{H}_{2} \mathrm{O}\right)$, schwertmannite (between $\mathrm{Fe}_{8} \mathrm{O}_{8}(\mathrm{OH})_{6} \mathrm{SO}_{4}$ and $\mathrm{Fe}_{16} \mathrm{O}_{16}(\mathrm{OH})_{10}\left(\mathrm{SO}_{4}\right)_{3}$ ) and goethite $(\mathrm{FeO}(\mathrm{OH}))$, as well the more stable secondary jarosite $\left(\mathrm{KFe}_{3}\left(\mathrm{SO}_{4}\right)_{2}(\mathrm{OH})_{6}\right)$ and hematite $\left(\mathrm{Fe}_{2} \mathrm{O}_{3}\right)$ depending on the geochemical conditions. Bernhard (2014) stated the pyrite oxidation can be considered to occur in three major steps: (1) the oxidation of sulfur Equation 1; (2) the oxidation of ferrous iron Equation 2 and 3 the hydrolysis and precipitation of ferric complexes and minerals (Equation 4):

$$
\begin{aligned}
& \mathrm{FeS}_{2}+7 / 2 \mathrm{O}_{2}+\mathrm{H}_{2} \mathrm{O} \rightarrow \mathrm{Fe}^{2+}+2 \mathrm{SO}_{4}{ }^{2-}+2 \mathrm{H}^{+} \\
& \mathrm{Fe}^{2+}+1 / 4 \mathrm{O}_{2}+\mathrm{H}^{+} \rightarrow \mathrm{Fe}^{3+}+1 / 2 \mathrm{H}_{2} \mathrm{O} \\
& \mathrm{FeS}_{2}+14 \mathrm{Fe}^{3+}+8 \mathrm{H}_{2} \mathrm{O} \rightarrow 15 \mathrm{Fe}^{2+}+2 \mathrm{SO}_{4}^{2-}+16 \mathrm{H}^{+} \\
& \mathrm{Fe}^{3+}+3 \mathrm{H}_{2} \mathrm{O} \rightarrow \mathrm{Fe}(\mathrm{OH})_{3}(\mathrm{~s})+3 \mathrm{H}^{+}
\end{aligned}
$$

Equation 1 marks the initial step for oxidation of pyrite in the presence of oxygen. $\mathrm{Fe}^{2+}$ and $\mathrm{H}^{+}$are removed into the environment that flows from the mine tunnels to surface water or groundwater. At low $\mathrm{pH}$ condition, the oxidation process of ferrous ion $\left(\mathrm{Fe}^{2+}\right)$ to ferric ion $\left(\mathrm{Fe}^{3+}\right)$ is strongly accelerated by microbiological activity Equation 2, producing ferric iron as the primary oxidant of pyrite (Equation 3). Under abiotic conditions, the rate of oxidation of ferrous iron was decreases rapidly with decreasing $\mathrm{pH}$ and at $\mathrm{pH}$ below than 3 , the oxidation of pyrite by ferric iron is about 10 to 100 times faster than by oxygen (Ritchie et al., 1994). The hydrolysis and precipitation of $\mathrm{Fe}$ hydroxides will release acidity condition from this process. The ferric ion hydroxide forms a yellowish-orange precipitate that exchange the acidic water solution in the streams to an orange or red color and covers the stream bed with a slimy sheeting. Thus, below $\mathrm{pH}$ of 2 , ferric hydrolysis products like $\mathrm{Fe}(\mathrm{OH})_{3}$ are not stable and $\mathrm{Fe}^{3+}$ continue to exist in the solution. The oxidation of pyrite is relates to sulfide minerals revealed to oxidizing conditions (e.g., chalcopyrite, bornite, molybdenite, arsenopyrite, enargite, galena and sphalerite etc.). In this process, different amounts of protons are released (Equation 4) and the other metals, elements or compounds are released to the environment. Hefa et al. (2009) said the existence of arsenic, lead, cadmium, pyrite, sulfides of copper and zinc in the drainage tailing piles go through same geochemical reactions to release more hidrogen and toxicity of metals into the mine drainage.
Acid mine drainage still occurs from hard-rock mine because of the bad impacts of water quality from acid mine drainage. However, industrial waste such as slag is a by-product formed in smelting and other metallurgical processes. There are three types of slag which is the blast furnace slag used for the production of cement. The second type is Blast of a Furnace (BOF) that has a high content of $\mathrm{FeO}$ used in cement and concrete production (Narottam et al., 2015). The third type of slag is Ladle Furnace Slag (LFS) generated during the secondary steel making in the ladle furnace slag. Fly ash (FA) is a product resulted from the coal combustion in the electric utility or industrial boilers. Four types of coal-fired boilers which are cyclone, Pulverized Coal (PC), stoker-fired and Fluidized-Bed Combustion (FBC). The PC boiler is the most normally used for electric generating units. The other boilers are more common at industrial facilities. Meanwhile, Biomass Ash (BA) is one of important non-fossil resources and its combustion or co-combustion with hard coal in power. The mineral content of biomass ash is very differ especially from fly ash (Michalik and Wilczynska, 2012).

The surface of drainage water at Bukit Besi, Terengganu are strongly polluted and found very acidic according to $\mathrm{pH}$ value $(\mathrm{pH}<3.5)$ and the content of metals very rich due to the existence of sulfide minerals. Therefore, the furture studies was constructed to determine the treatment efficiency for an acid mine drainage by using industrial waste such as LFS, BA and FA as sorbent materials. For the tests, a treatment system consisting of a continuously stirred tank was operated by using actual AMD from mining site and applied to understand the effects of different type of sorbents used with retention time. However, the main objective of this experimental work was to find out a study about the efficiency of sorption by waste industrial materials with respect to the heavy metals immobilization. Moreover, the experiment was carry out to investigate more about the applicability of these low-cost adsorbent materials for the decontamination of AMD. Presented here, therefore, is the remediation of heavy metals in acid mine Water using industrial waste by-products.

\section{Materials and Methods}

\section{Sampling Site}

The study area located in Bukit Besi, Terengganu with longitude and latitude $\left(4^{\circ} 46^{\prime} \mathrm{N}, 103^{\circ} 12^{\prime} \mathrm{E} / 4.767^{\circ} \mathrm{N}\right.$, $103.2^{\circ} \mathrm{E}$ ) which ever part of Malaysia (Fig. 1). The surface water is orange-red-brown color due to the very high presence of ferric iron in the water. 


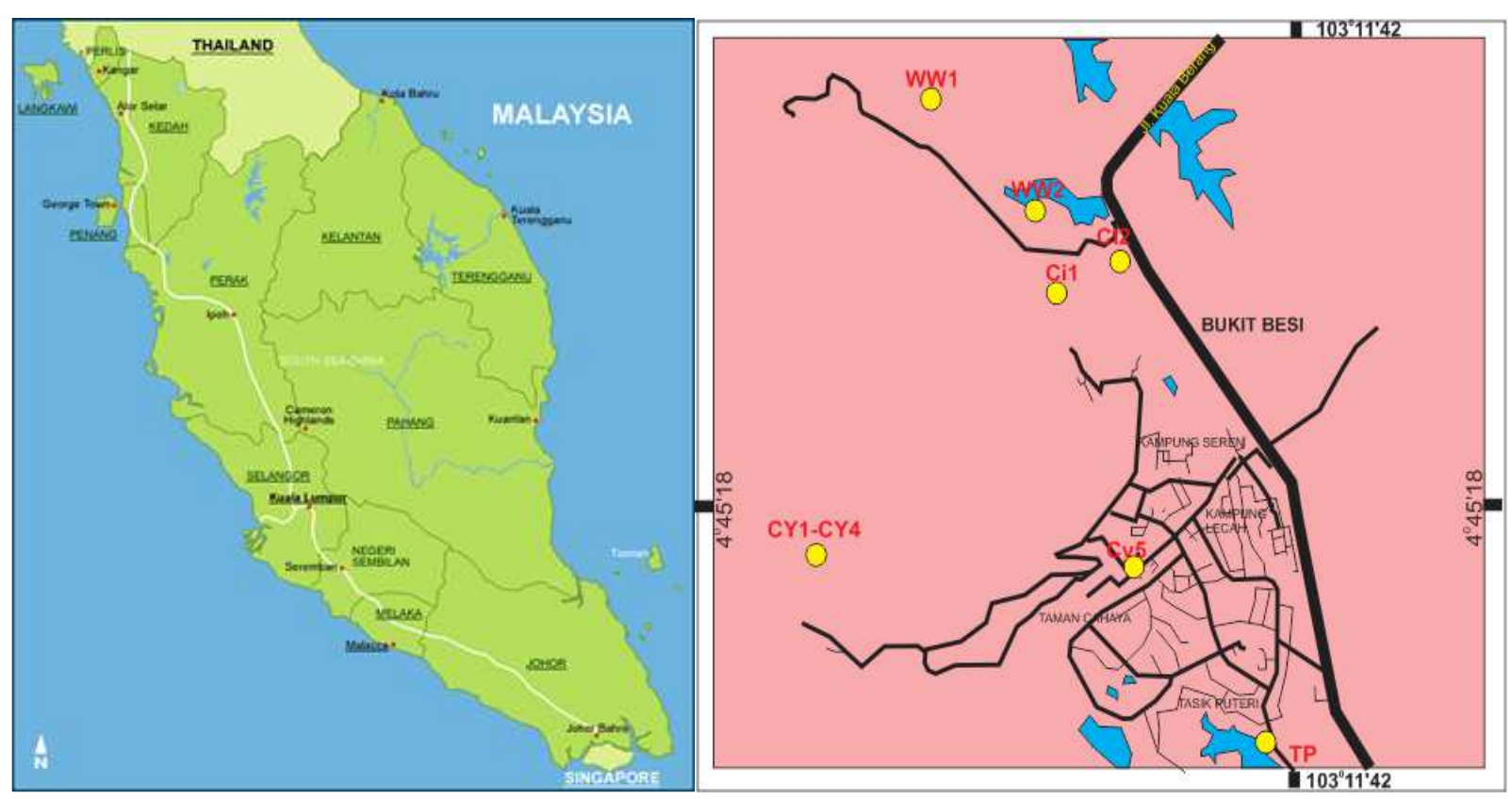

Fig. 1: Location of sampling site situated at east Bukit Besi, Dungun Terengganu

\section{Sample Collection}

AMD samples were collected for three (3) times at the same locations from the abandoned ponds deposit at the study area. The samples were collected into three different high-density polyethylene bottles into prepared for the sampling of high density polyethylene. On-site analyses of in-situ field parameters such as $\mathrm{pH}$, Electrical Conductivity (EC), total dissolved solution and physical characteristic were measured from in different surface drainage waters using Quality meter YSI 656. One liter (1L) of surface water were collected from each area, preserved and stored in a cool box at approximately $4^{\circ} \mathrm{C}$ before being transported to the laboratory for further analysis.

\section{Preparation and Characterization of Sorbents}

LFS sample was collected from a Megasteel factory located at Banting, Selangor. Samples were prepared by air-dried air-drying at room temperature for one week (7 days) before grinding using a mechanical grinder and again mortared manually to achieve the fine-pollen form of material. The fine-size of waste industrial samples were sieved using a manual sieved (standard test sieve ASTM II Specification) to obtain a particle size of 0.063 $\mathrm{mm}$ respectively. The characterization of LFS, FA and BA were carried out by X-Ray Diffraction (XRD), XRay Fluorescence (XRF) and Field Emission Scanning Electron Microscope (FESEM).

\section{Tank Preparation and Water Analyses}

AMD samples collected from the study area at the surface water from iron ore mine site in Bukit Besi, was sampled onsite and set up in three tanks for treating acidic drainage at the laboratory. The experimental tank was designed with silica glass materials $(18 \mathrm{~cm} \times 17.5 \mathrm{~cm}$ $\times 17.5 \mathrm{~cm})$ and each tank was set up with 200 gram of adsorbents and 4 liters of AMD water in ratios of 1:20 (for 200g of adsorbent material over $4000 \mathrm{ml}$ of AMD effluent) and stirred by using magnetic stirrer continuously for 50 days. The water analysis was conducted by using Inductively Coupled Plasma Mass Spectrometry (ICP-MS) (model, Perkin Elmer Elan 900) to detect the concentration of heavy metals and major cations. Major anions were conducted by filtered filtering the solution through Whatman filter paper $(0.2 \mu \mathrm{m}$ pore size membrane) and instrumental analyses were by using Ion chromatography (Metrohm 850 Professional) with chemical suppression in order to measure sulfate and chloride anion contents (Standard Methods, 4110).

\section{Results}

\section{Results of the Characterization of AMD Samples}

At Bukit Besi mining sites, acid mine drainage was strongly acidic and contained high significant levels of metal ions especially $\mathrm{Fe}^{3+}$ and sulfates $\left(\mathrm{SO}_{4}{ }^{2-}\right)$. The acidic characteristic of AMD results from the chemical reaction through sulfide minerals generally pyrite, that oxidizes and dissociates when exposed to water and air. Thus, the precipitation of $\mathrm{Fe}^{2+}$ to $\mathrm{Fe}^{3+}$ occurs and the oxidation of ferrous ion is subsequently reduced by pyrite. These, therefore, increased the acidity of the solution. The characteristic of AMD shows that the solutions were highly toxic to the organism and could affect ecosystem without 
any remediation. Field data of AMD showed low $\mathrm{pH}$ at a mean value of (2.12) and high potential production (Eh) value of $261(\mathrm{mV})$. Meanwhile, the EC recorded was at high concentration value of (mean: $2660 \mu \mathrm{s} / \mathrm{cm}$ ) with total dissolved solution values is at mean value of $1327.67 \mathrm{mg} / \mathrm{L}$ and salinity values are 1.09 (p.s.u). Table 1 illustrates the average concentration of heavy metals obtained from Bukit Besi mine and calculated concentration. The concentration of Fe was found to be excessively high compared to other heavy metals with range from 695.28 to $938.44 \mathrm{mg} / \mathrm{L}$, followed by $\mathrm{Mn}$ from 184.88 to $226.51 \mathrm{mg} / \mathrm{L}, \mathrm{Cu}$ from 10.52 to $10.9 \mathrm{mg} / \mathrm{L}, \mathrm{Zn}$ from 7.23 to $9.79 \mathrm{mg} / \mathrm{L}, \mathrm{Pb}$ from 1.75 to $2.08 \mathrm{mg} / \mathrm{L}$, Ni from 0.76 to $0.98 \mathrm{mg} / \mathrm{L}$ and As from 0.013 to $0.04 \mathrm{mg} / \mathrm{L}$. Meanwhile, for the concentration of anion displays excessively high values $\mathrm{SO}_{4}{ }^{2-}$ (4455.87 $\mathrm{mg} / \mathrm{L}$ ) and $\mathrm{Cl}^{-1}$ was at considerable concentrations at a low value of $2.466 \mathrm{mg} / \mathrm{L}$. The values of heavy metals have exceeded the concentration of the compared standard set by Environmental Quality Act (1974) and Water Quality Standard (2000). EQA standard is the legislation that is related to the prevention, abatement, control of pollution and enhancement of the environment in Malaysia. The Act restricts the discharge of wastes into the environment in contravention of the acceptable conditions.

\section{Results of the Characterization of the Sorbent}

Figure 2 illustrates the XRD patterns and FESEM images of the different sorbents used in this study. FA mainly consist of a variety of crystalline phases identified by more than ten sharp peaks (Fig. 2a). The primary crystalline phases are quartz as identified by the sharp peaks. These primary crystalline phases are quartz and mullite. The X-Ray diffraction analysis of the BA shows a very smooth pattern with a very sharp peak identified by lesser no of $(<10$ peaks) (Fig. 2b). The high peak identified a higher contents of $\mathrm{Si}$ associated with the presence of quartz as the primary crystalline phases. While for LFS, there are differences in crystalline phases between other ashes. LFS contains very low content of $\mathrm{SiO}_{2}$ and $\mathrm{MgO}$ but has a higher contents of major impurities such as $\mathrm{Ca}$ and a higher content of $\mathrm{Al}_{2} \mathrm{O}_{3}$ (Fig. 2c).
FESEM images of FA reveals that the particles of FA are predominantly spherical in shape and shows a nano blocky-like shape with the vitreous amorphous material. Quartz is the dominant mineral phase as indicated by the consolidated with the biotically-precipitate image with a range of size between $100 \mathrm{~nm}$ to $300 \mathrm{~nm}$ respectively. The homogenous spherical FA particles are easily recognizable. Ellipsoidal pores can be identified as "cellular structure". This is due to total or partial melting of clayey particle associated with the escape of trapped gases in the matrix of the samples. The FA particles, however, do not melt even at temperature as high as $10000 \mathrm{C}$. Figure $2 \mathrm{~b}$ indicates the crystal morphology of BA. The image shows a lot of amorphous silica that exists and retains their initial microstructure. The size of particles that occurred in irregular-shaped of biomass morphology range between 10 $\mathrm{nm}$ to more than $200 \mathrm{~nm}$ respectively. Besides, their nonhomogeneous and coralloid crystal is observed.

The FESEM image of LFS is characterized by large clusters of radiating tetragonal prisms cemented together with homogeneous particles with rough surfaces. The characteristic morphology of LFS is illustrated in Fig. 2c as single large tetragonal-like prisms crystal (range of length is between $800 \mathrm{~nm}$ in size), which have grown at the expenses of an intergrowth of octahedral polycrystals that is growing onto the surface. Besides, it mainly composed of hierarchical pyramids with an assembly of nanopyramids. These prepared nanopyramids have edge length of $100 \mathrm{~nm}$ to $200 \mathrm{~nm}$ respectively. The chemical composition of fly ash, biomass ash and slag as determined by X-ray Fluorescence (XRF) is given in Table 2. As summarized in Table 2, slag and fly ash contain high percentage of $\mathrm{CaO}(>50 \%)$, meanwhile biomass ash contains high percentage of $\mathrm{SiO}_{2}(>40 \%)$. The composition of slag also contain high content of $\mathrm{Al}_{2} \mathrm{O}_{3}$ (21.23\%), $\mathrm{ZrO}_{2}$ (11.91\%), $\mathrm{MgO}$ (5.96\%) and $\mathrm{SiO}_{2}$ $(5.14 \%)$ but low content of $\mathrm{MnO}, \mathrm{Cl}$ and $\mathrm{SrO}(<0.10 \%)$ respectively, the fly ash contains high percentage of $\mathrm{SiO}_{2}$ (13.88\%), $\mathrm{Al}_{2} \mathrm{O}_{3} \quad(7.35 \%)$ and $\mathrm{MgO}$ (2.34\%) while biomass ash displays high percentage of $\mathrm{CaO}(12.97 \%)$, $\mathrm{K}_{2} \mathrm{O}(12.41 \%), \mathrm{Al}_{2} \mathrm{O}_{3}(4.76 \%)$ and $\mathrm{Fe}_{2} \mathrm{O}_{3}(4.27 \%)$.

Table 1: Average concentration of heavy metals and ions for Bukit Besi mine as compared EQA and WQS standard

\begin{tabular}{llll}
\hline Elements & Concentration $(\mathrm{mg} / \mathrm{L})$ & EQA $1974(\mathrm{mg} / \mathrm{L})$ & WQS 2000 $(\mathrm{mg} / \mathrm{L})$ \\
\hline $\mathrm{Pb}$ & 1.877 & 0.1 & 0.01 \\
$\mathrm{Fe}$ & $\begin{array}{l}(1.751-2.075) \\
(695.029\end{array}$ & 1 & 0.3 \\
$\mathrm{Mn}$ & $\begin{array}{l}199.673-938.438) \\
(184.876-226.512)\end{array}$ & - & 0.1 \\
$\mathrm{Cu}$ & 10.704 & 0.2 & - \\
$\mathrm{Ni}$ & $(10.518-10.9)$ & 0.2 & - \\
$\mathrm{Zn}$ & $(0.861$ & 2 & 0.3 \\
$\mathrm{As}$ & 8.328 & & 0.01 \\
$\mathrm{SO}_{4}{ }^{2-}$ & $(7.231-9.785)$ & 0.05 & 250 \\
$\mathrm{Cl}^{-}$ & $(0.013-0.04)$ & 0.5 & 250 \\
\hline
\end{tabular}


Nuur Hani Mohammed et al. / American Journal of Engineering and Applied Sciences 2017, 10 (4): 1001.1012 DOI: 10.3844/ajeassp.2017.1001.1012

Table 2: Chemical composition of slag, fly ash and biomass ash by X-Ray Fluorescence

\begin{tabular}{lrrr}
\hline $\mathrm{Chemical}$ composition (\%) & LFS & \multicolumn{1}{c}{ FA } & \multicolumn{1}{c}{ BA } \\
\hline $\mathrm{CaO}$ & 51.52 & 57.24 & 72.97 \\
$\mathrm{Al}_{2} \mathrm{O}_{3}$ & 21.23 & 7.35 & 4.76 \\
$\mathrm{MgO}$ & 5.96 & 2.34 & 2.81 \\
$\mathrm{SiO}_{2}$ & 5.14 & 13.88 & 43.07 \\
$\mathrm{SO}_{3}$ & 3.31 & 0.91 & 0.81 \\
$\mathrm{Fe}_{2} \mathrm{O}_{3}$ & 0.64 & 0.87 & 4.27 \\
$\mathrm{TiO}_{2}$ & 0.12 & 0.40 & 0.30 \\
$\mathrm{WO}_{3}$ & 0.08 & 0.00 & 0.00 \\
$\mathrm{MnO}$ & 0.04 & 0.03 & 0.11 \\
$\mathrm{Cl}$ & 0.03 & 0.23 & 0.69 \\
$\mathrm{SrO}$ & 0.02 & 0.05 & 0.02 \\
$\mathrm{ZrO}_{2}$ & 11.91 & 0.02 & 0.02 \\
$\mathrm{~K}_{2} \mathrm{O}$ & 0.00 & 0.35 & 12.41 \\
$\mathrm{P}_{2} \mathrm{O}_{5}$ & 0.00 & 0.18 & 2.81 \\
$\mathrm{Na}_{2} \mathrm{O}$ & 0.00 & 0.29 & 0.07 \\
$\mathrm{CuO}_{\mathrm{ZnO}}$ & 0.00 & 0.06 & 0.04 \\
$\mathrm{Rb}_{2} \mathrm{O}$ & 0.00 & 0.02 & 0.03 \\
$\mathrm{Cr}_{2} \mathrm{O}_{3}$ & 0.00 & 0.00 & 0.02 \\
\hline
\end{tabular}

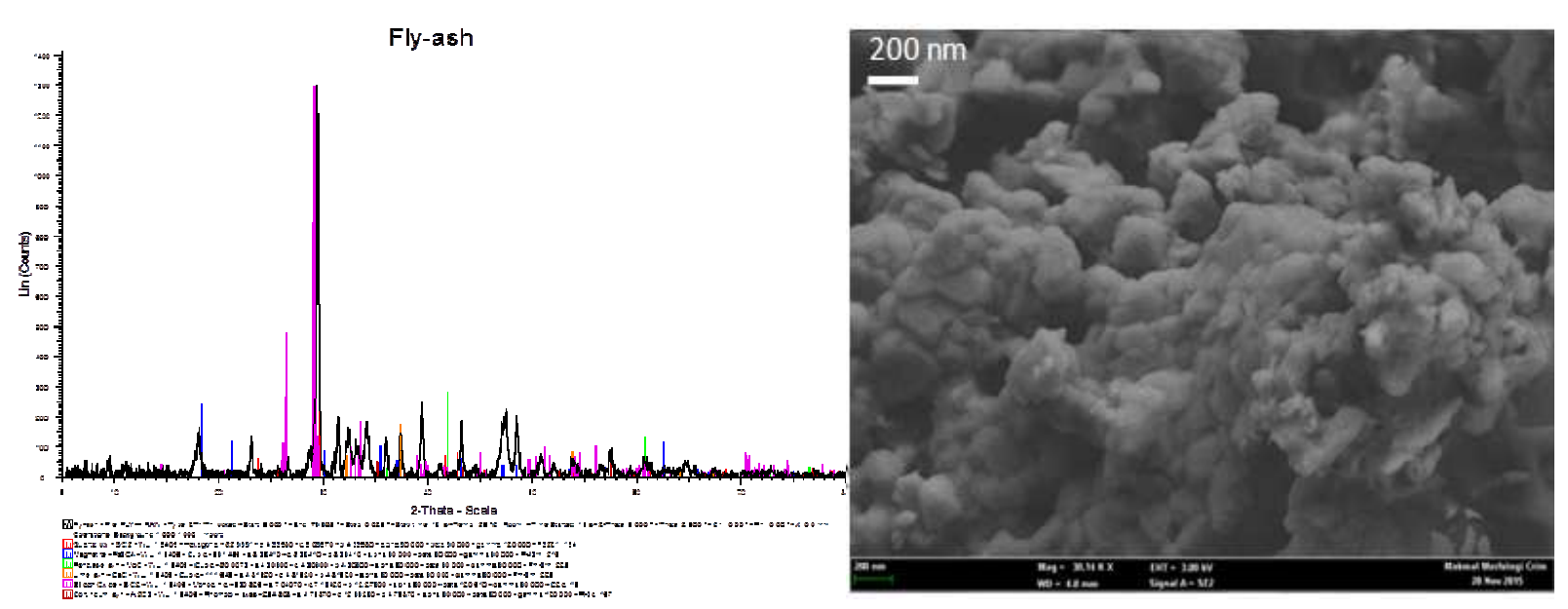

(a)



(b) 


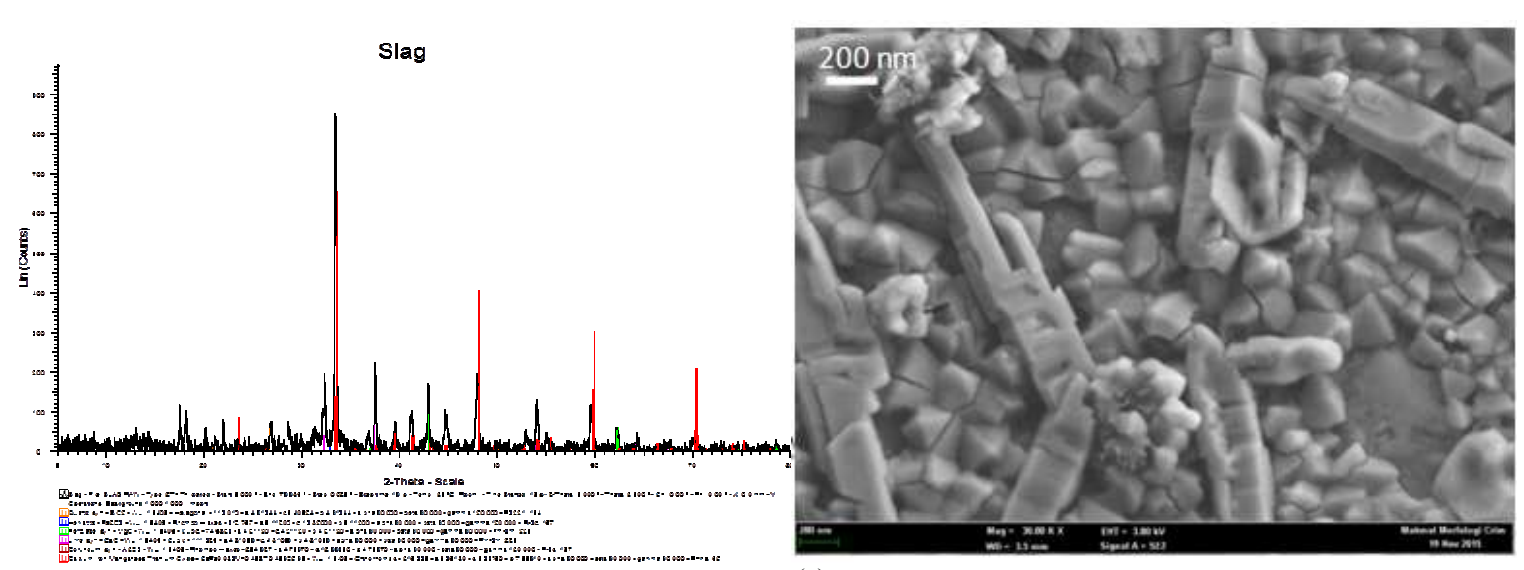

(c)

Fig. 2: XRD patterns of slag (LFS), fly ash and biomass ash with FESEM images at the right side for magnification $30 \mathrm{x}$ : (a) Fly Ash (FA) (b) Biomass Ash (BA) and (c) Slag (LFS)

\section{Results on AMD Treatment Using Fly Ash, Ladle Furnace Slag and Biomass Ash}

The kinetics of the neutralization reaction was investigated by monitoring the $\mathrm{pH}$, the reduction potential (eh) and electrical conductivity of AMD solution for 50 days. The initial $\mathrm{pH}$ for acid mine drainage before remediation was initially very low (2.12) which is very acidic for human life and aquatic ecosystem. Meanwhile, the initial reduction potential of AMD was $261(\mathrm{mV})$ and the conductivity value was excessively high at $2660(\mu \mathrm{S} / \mathrm{cm})$ due to the acidity condition of the water. Figure 3 shows the $\mathrm{pH}$ change for the neutralization reactions between investigated sorbents and the AMD. A small increase of the initial $\mathrm{pH}$ (2.12) occurred on contact with LFS (2.60), FA (2.57) and BA (2.54). Based on 50 days of operation, the trends of LFS and FA were rapidly increased from day 1 to day six and show the slight increase after day 6 .

Meanwhile, $\mathrm{pH}$ of $\mathrm{BA}$ change rapidly from starting day 1 up untill day 11 and progressed slightly onwards for the remaining days. The opinion that the $\mathrm{pH}$ increases as a consequence of the progressive dissolution of the sorbent during the reaction and conversely can be decreased due to the release of relict organic matter (Rios et al., 2008). The final $\mathrm{pH}$ at 50 days of treatment ranges from 2.6 to 7.3 for slag, 2.57 to 7.09 (FA) and 2.54 to 6.8 (BA). Figure 4 illustrates the reduction potential $(\mathrm{mV})$ trend of three waste materials. The reduction potential $(\mathrm{mV})$ graph shows decreasing trend in contrast with increasing $\mathrm{pH}$ values. Figure 4 show gradually downward pattern for three adsorbent materials. At day 1 to day 6 , reduction potential $(\mathrm{mV})$ values for LFS was rapidly declining and at day 6 were gradually declining, while BA shows slight changes after day 11 and onward. At day 22 to day 24, FA trends show sudden increase trend before going down because of sudden increasing activity of the oxidized component.

As compared with Fig. 3 and 4, the $\mathrm{pH}$ and eh graph show inversely variation patterns in such a way that as
$\mathrm{pH}$ values of AMD decreases, eh (mv) increases due to a rise in $\mathrm{H}^{+}$activity from the existence of pyrite, sulfides of copper, zinc, cadmium, lead and arsenic in the drainage. Meanwhile, the reduction potential $(\mathrm{mV})$ decreased with high $\mathrm{pH}$ because of increasing activity of the reduced components. Figure 5 demonstrates the Electrical Conductivity (EC) trends for FA, LFS and BA in tank analysis operation with time (50 days). The EC of acid mine drainage shows a sharp drop from the initial value of $2660(\mu \mathrm{S} / \mathrm{cm})$ to $280(\mu \mathrm{S} / \mathrm{cm})$ for $\mathrm{LFS}$, while $283(\mu \mathrm{S} / \mathrm{cm})$ for $\mathrm{FA}$ and $457(\mu \mathrm{S} / \mathrm{cm})$ for $\mathrm{BA}$ respectively for day 1 contact. The pattern of the graph for the three adsorbents show similar pattern which is regularly and systematically decreased with the exception of FA which decreased abruptly at day 28 . This sudden decrease can be associated with sulfate reduction. According to (Kumar et al., 2008), BA and LFS show a steady decrease in electrical conductivity as contaminant species are removed from solution by precipitation or adsorption onto sorbent particles.

The immobilization of metal ions from aqueous solutions is a very complicated process involving ion exchange, adsorption and precipitation of hydroxides on active sites (Gitari et al., 2006). The removal of heavy metals from AMD using three adsorbents (LFS, FA and BA) is illustrated in Fig. 6a-6h for a sorbent: AMD mixture of ratio 1:20. As shown in Fig. 6a, Pb showed a steep decrease at day 1 to day 6 using BA and FA, followed by a slight progressive increase during day 6 to day 11 before a final steadily decrease for FA. After day 6 to day 28 , the removal of $\mathrm{Pb}$ for biomass ash showed uncertain trend and steadily decrease after day 28 onward. Meanwhile, by using LFS, the immobilization of $\mathrm{Pb}$ showed a sharply declining trend from starting day 1 to day 11 followed by a suddenly rising increase between day 11 and day 18, with slight fluctuating concentrations and a decrease onwards before start decreasing after that. The concentration of $\mathrm{Pb}$ become constant and was almost near to $0 \mathrm{mg} / \mathrm{L}$ from day 21 onward. 


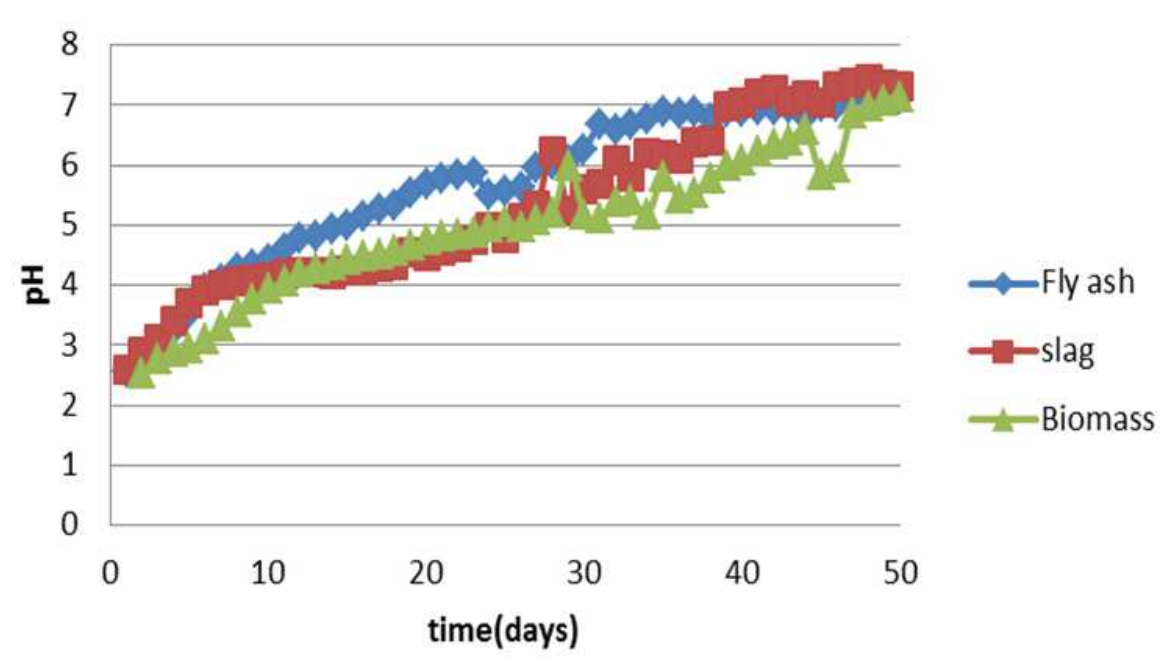

Fig. 3: Variation of $\mathrm{pH}$ for slag, biomass ash and fly ash during remediation test operated with time 50 days

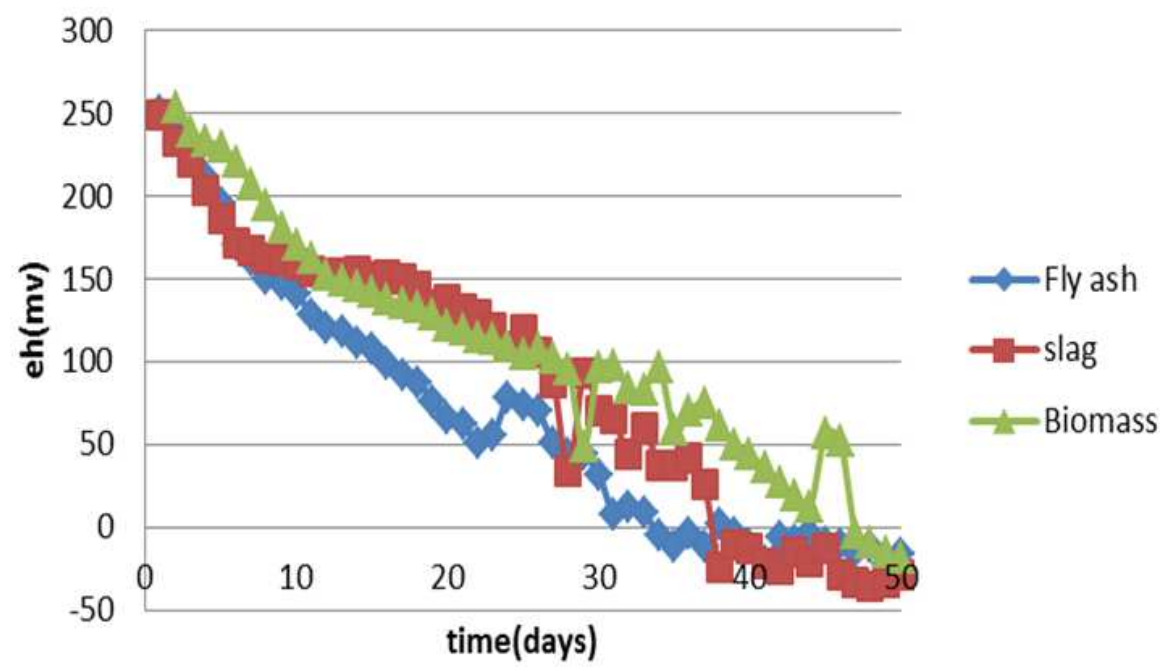

Fig. 4: Reduction potential of three sorbent materials during remediation test operated with time 50 days

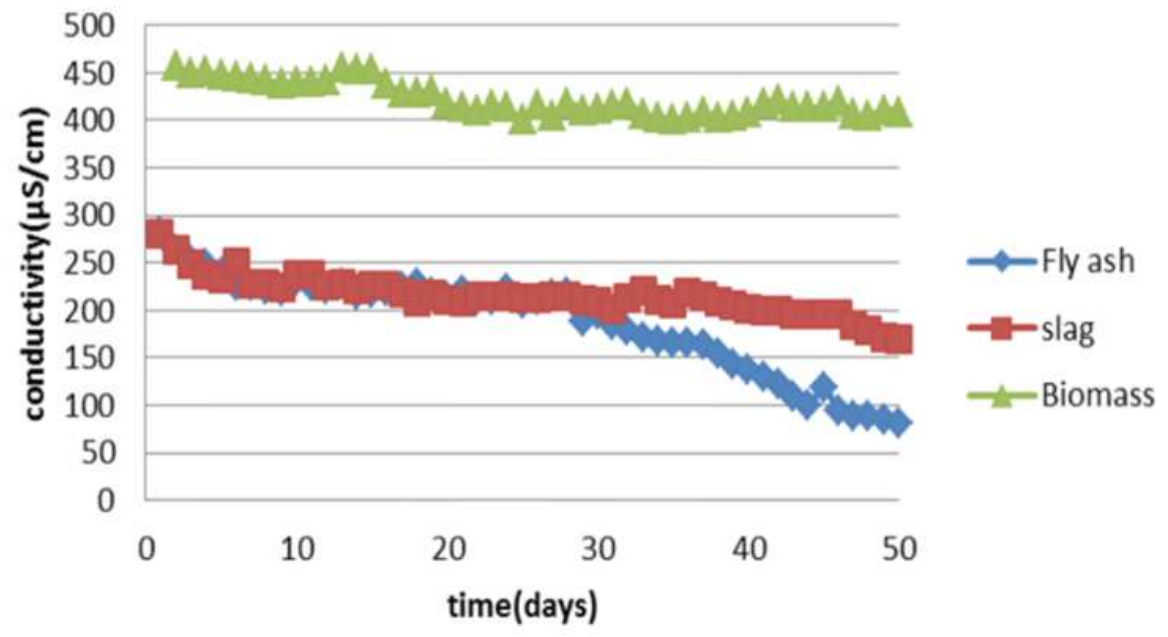

Fig. 5: Electric conductivity of AMD solution operated in tank analysis with time (50 days) 


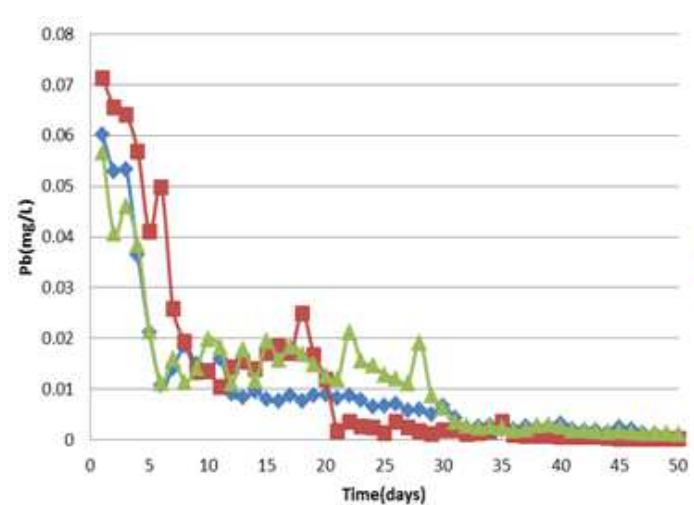

(a)

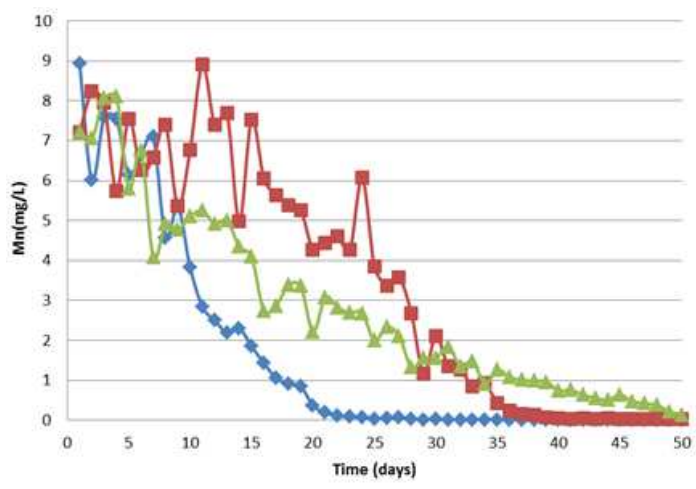

(c)

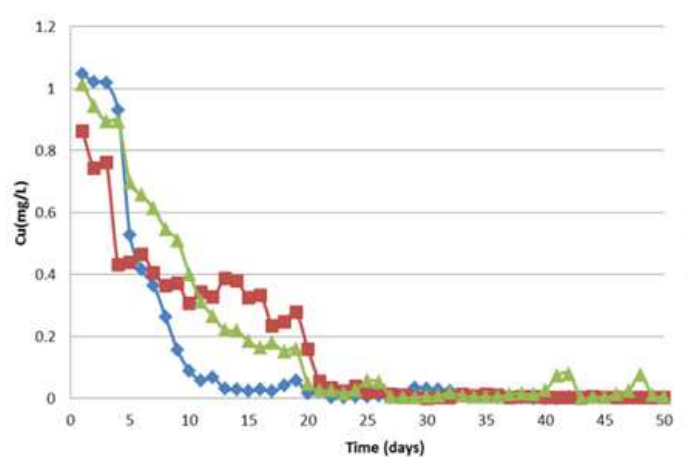

(e)

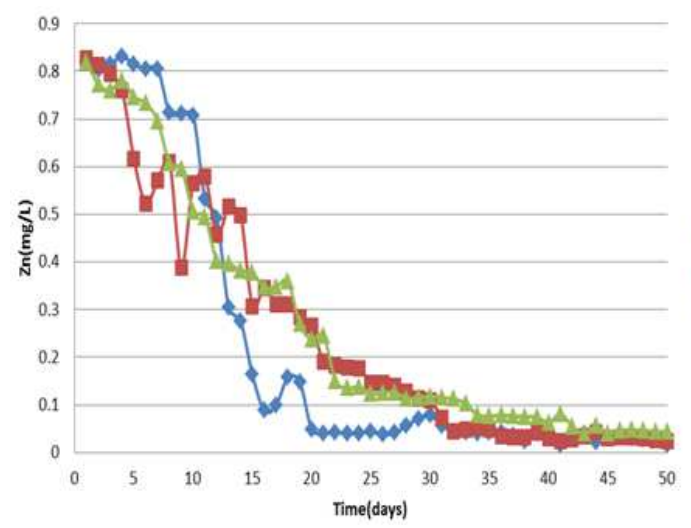

(g)

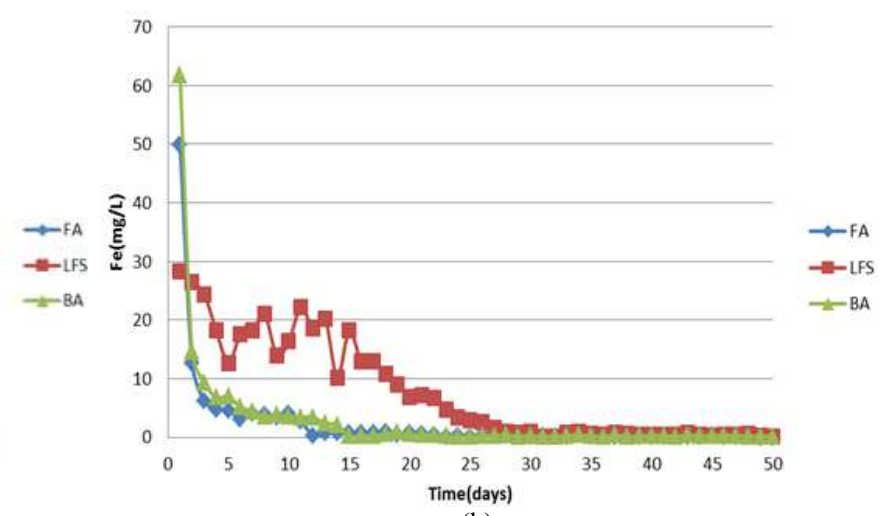

(b)

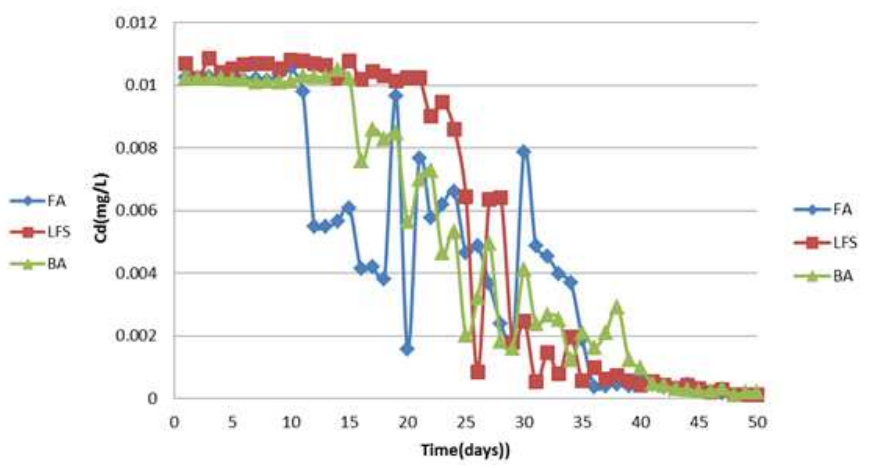

(d)

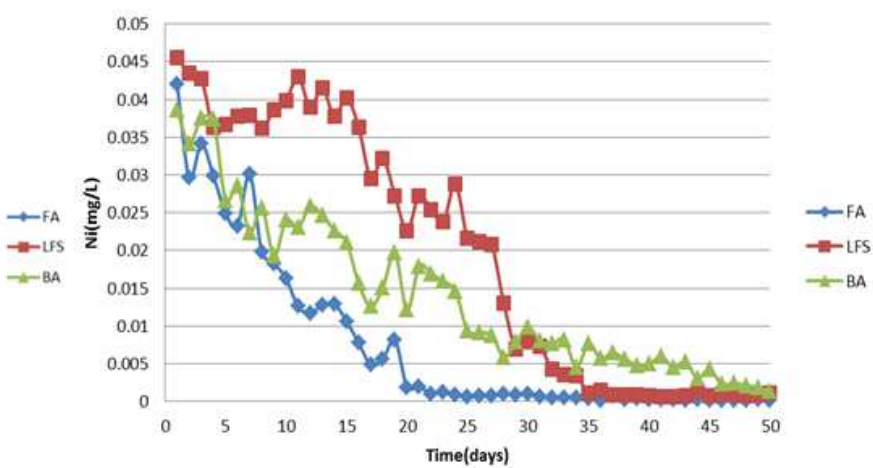

(f)

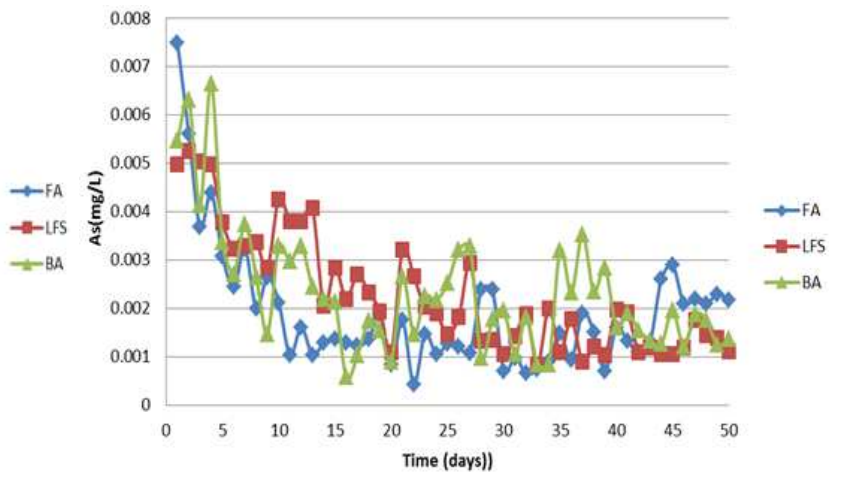

(h)

Fig. 6: Variation of concentration of metals as a function of time during tank analysis with ratio 1:20 for 50 days 
In the case of Fe (Fig. 6b), biomass and fly ash produced a steep decrease at the beginning (day 1 ) to day 7 followed by small fluctuations at day 5 and day 8 . At day 8 , the iron concentrations were reached with very low residual concentration for the rest of the time intervals, with almost complete removal. LFS showed a lower efficiency than other absorbents, producing a rapidly decrease up to day 5. A sudden increase was observed at day 6 and then declined at day 8 followed by new rising on day 9 . The content of $\mathrm{Fe}$ at day 15 again starts to decline and remain stable for the removal of $\mathrm{Fe}$ at day 30 onward. Therefore, this observed Fe trend for LFS showed an inconsistent behavior in concentration characterized by significant concentration fluctuations.

The removal of Mn from AMD illustrated in Fig. 6c, at the beginning as AMD was in contact with sorbent materials, the immobilization of $\mathrm{Mn}$ showed inconsistent trends. The removal of $\mathrm{Mn}$ seems to be more effective for fly ash as shown by a steady decrease at day 8 and became stable at day 20. Meanwhile, LFS and biomass ash showed very less efficiency to remove Mn due to unstable immobilize patterns. At day 35, a slight decline was observed for biomass ash and the removal remains constant at day 40 in the case of LFS.

The removal of $\mathrm{Cd}$ at the beginning showed a small increased fluctuation for fly ash and slag while for biomass ash displayed decrease fluctuation before steeply decreasing. The immobilization of cadmium also showed inconsistency trends for all adsorbent materials before beginning to be stable at day 30 onward. $\mathrm{Cu}$ concentration is illustrated in Fig. 6e and is characterized by gradually decrease at the beginning of the reaction. There was a small decreased fluctuations at day 2 to day 4 before steeply decrease again onwards. A steep decrease was observed again at day 3 to day 7 for fly ash before steeply decrease and then remained stable at day 10. There were three small fluctuations from day 11 to day 19 before a steady decrease onwards for LFS and removal was almost nearly completed at day 21 for both LFS and biomass ash respectively. In general, for removal of Ni (Fig. 6f) by using LFS sample showed a small decrease before a steady increase at day 4 to day 11 and gradually decreased with small fluctuations onwards and the beginning of to complete remove of $\mathrm{Ni}$ ion at day 35. There was a small decreased fluctuation for both biomass and fly ash observed at the beginning of the reaction. Fly ash sample showed steady decrease than biomass ash which produced inconsistent trend characterized by concentration fluctuation and reversible behavior concentration at day 20 .

In the case of $\mathrm{Zn}$ (Fig. 6g), fly ash and biomass sample produced similar trends for $\mathrm{Zn}$ after contact with small decreased fluctuation at the beginning of the reaction, while LFS sample showed small increased fluctuation. After day 3, all sorbents decrease very gradually with inconsistent small fluctuation. The concentration of $\mathrm{Zn}$ was very stable at day 20 for fly ash and day 30, the removal of $\mathrm{Zn}$ was complete for slag and biomass samples. Figure 6(h) illustrated removal concentration of As. All sorbents produced similar trends for As with inconsistent decrease immobilization of metal ion from the beginning of day 1 day to the end of the analysis at day 50 .

The kinetics of metals removal from three remediation tank containing different absorbents material are shown in Table 3 and Fig. 7. The removal percentage is expressed by this equation:

$$
R E(\%)=\frac{\left(C_{0}-C_{e} \times 100\right)}{C_{0}}
$$

$$
\begin{aligned}
& R e=\text { Removal efficiency } \\
& C_{0}=\text { Initial concentration } \\
& C_{e}=\text { Equilibrated concentration }
\end{aligned}
$$

Regarding the comparison removal efficiency in remediation system, it was verified that FA adsorbent has a great efficiency to adsorb more Mn $(99.99 \%)$ compared to LFS (99.89) and BA (99.34\%). Besides, FA shows good adsorption characteristics toward the removal of $\mathrm{Fe}, \mathrm{Ni}$ and $\mathrm{Cu}$ with percentage 99.97, 99.84 and $99.69 \%$ respectively. LFS adsorbent has the high ability to remove the $\mathrm{Pb}(99.95 \%), \mathrm{Mn}(99.89 \%)$ and $\mathrm{Fe}$

\begin{tabular}{|c|c|c|c|}
\hline \multirow[b]{2}{*}{ Metals } & \multicolumn{3}{|c|}{ Removal efficiency (\%) } \\
\hline & FA & LFS & $\mathrm{BA}$ \\
\hline$\overline{\mathrm{Cu}}$ & 99.69 & 99.69 & 99.69 \\
\hline $\mathrm{Zn}$ & 98.05 & 97.18 & 94.80 \\
\hline $\mathrm{Pb}$ & 99.65 & 99.95 & 99.42 \\
\hline $\mathrm{Fe}$ & 99.97 & 99.78 & 99.79 \\
\hline $\mathrm{Mn}$ & 99.99 & 99.89 & 99.34 \\
\hline $\mathrm{Ni}$ & 99.84 & 98.71 & 98.51 \\
\hline As & 78.20 & 88.80 & 86.40 \\
\hline $\mathrm{Cd}$ & 98.78 & 98.81 & 97.87 \\
\hline
\end{tabular}
(99.78\%) effectively, meanwhile BA adsorbent can adsorb more $\mathrm{Fe}(99.79 \%)$ and $\mathrm{Cu}(99.69 \%)$.

Table 3: Removal efficiency (\%) for fly ash, LFS and biomass ash at last day of remediation 


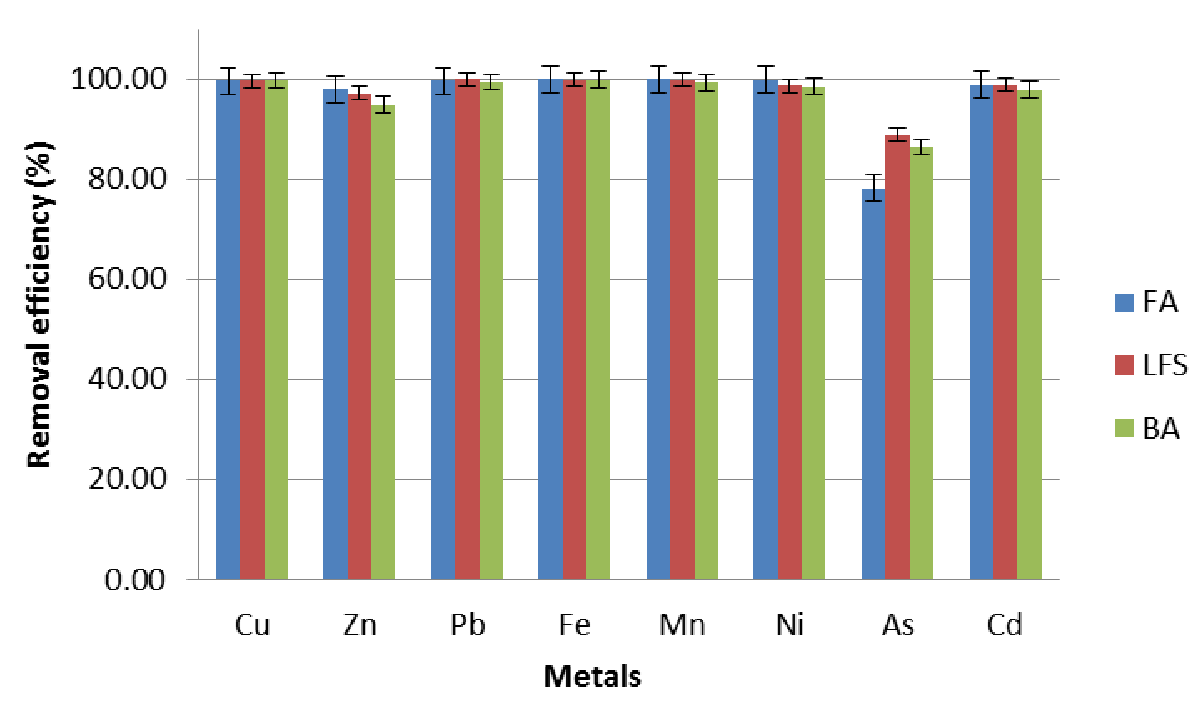

Fig. 7: Comparison between removal efficiency for three adsorbents of metals immobilization

\section{Discussion}

Table 1 showed the analysis of cation and anion from AMD solution have high content of $\mathrm{SO}_{4}{ }^{2-}(4455.87$ $\mathrm{mg} / \mathrm{L})$ and others metal such as Fe $(822.029 \mathrm{mg} / \mathrm{L}), \mathrm{Mn}$ $(199.67 \mathrm{mg} / \mathrm{L}), \mathrm{Cu}(10.704 \mathrm{mg} / \mathrm{L})$ and $\mathrm{Zn}(8.328 \mathrm{mg} / \mathrm{L})$. Sulfate is a major anion occurring in the chemical and metallurgical processing industries especially in mine drainages either in neutral or in acidic phases (Cao et al., 2008). Compared with toxic metals, $\mathrm{SO}_{4}{ }^{2-}$ is only mildly hazardous. This gives the reason many countries have no set guidelines for $\mathrm{SO}_{4}{ }^{2-}$.

FESEM images and XRD analysis (Fig. 2) were analized to further characterize the adsorbents particles. This is supported by the results of the chemical composition in Table 2 that showed a high content of $\mathrm{CaO}$ $(>50 \%)$ found in both LFS and fly ash material. Silica and alumina are identified as acid constituents by the metallurgist and mineralogist in natural or synthetic mineral composition and they produce a weak acid solution in the presence of moisture. While $\mathrm{CaO}$ and $\mathrm{MgO}$ are basic constituents and can produce a strongly alkaline reaction in the presence of moisture (Fontana and Greene, 1967). The $\mathrm{pH}$ of the reaction between LFS and water is always alkaline normally in the range of 9 to 11 . In fact, LFS is regularly used to remove acid conditions in industrial mining as well as to neutralize acid soil in agriculture. The alkaline fly ash is very rich in Ca content meanwhile alkaline $\mathrm{pH}$ phase indicates the presence of amorphous lime $(\mathrm{CaO})$ found in fly ash (Ghanashyam and Rona, 2013). The biomass composition is dominated by $\mathrm{SiO}_{2}(43.07 \%)$ and $\mathrm{CaO}(12.97 \%)$ and contains lesser amounts of $\mathrm{Mg}, \mathrm{Al}, \mathrm{K}$ and P-oxides. The metal uptake through sorbents primarily very depending on size of the crystal, chemical composition and morphology of the minerals (Nunes et al., 2016; Rios et al., 2008).

Hendricks (2005) agreed the process of precipitation occur on the surface of ion exchanger may be induced and can act as crystallization seeds for the subsequent of the ions. This therefore concludes that precipitation is the main mechanism for metal uptake and the addition of sorbents will decreases the metal concentration while increasing the $\mathrm{pH}$ because of precipitation process on the surface of the sorbents. The process of precipitation works on the basis that the $\mathrm{pH}$ is reached at which the metals attain their minimum solubility and as such precipitate out. However, each metals display its own minimum solubility at its own $\mathrm{pH}$ characteristic. The $\mathrm{pH}$ required to precipitate most metals from water ranges from $\mathrm{pH}$ 6- $\mathrm{pH} 9$ (except for $\mathrm{Fe} \mathrm{pH}>3.5$ ), thus if alkaline material is added, such that the $\mathrm{pH}$ is raised up to 9 , most of metals will be hydrolyzed and precipitated. The mine drainage is characterized by the $\mathrm{pH}$ of AMD that can be as low as -4 and often discolored because of the presence of $\mathrm{Fe}^{2+}$ and $\mathrm{Fe}^{3+}$ (Cullen and Rheimer, 1989). Adsorption of toxic metals are very complex due to connection between the properties of the $\mathrm{pH}$, the solid surface and the concentration of competing ions speciation (Sadiq, 1997).

As discussed by Cooney (1998), chemical reactions play an important role in the metals sorption were not thought to control the sorption process kinetics. The mechanism of sorption was tested by ICP through stirred tank experiment as shown in Fig. 6 (a-h). Through 50 days of operation have shown all toxic element in mine water completely removed by sequences of fly ash $>$ LFS > biomass (Silva et al., 2012). The mine water contained a high concentration of $\mathrm{Fe}(822.029 \mathrm{Mg} / \mathrm{L})$ and after in contact with fly ash and biomass ash within 5 
days of treatment, Fe content was completely removed (Fig. 6b). The polluted water specified by an orange or yellowish-orange color, indicating high levels of $\mathrm{Fe}^{3+}$ and smell like rotten egg-like hydrogen sulfide (Hefa et al., 2009). The time of contact between adsorbent can be ascertained by the rate of adsorption.

At day 10 of operation, the species of $\mathrm{Cu}$ was decreased and was completely removed by using fly ash material. After 20 days of operation work, fly ash showed the effectiveness of a sorbent material to remove all toxic metals such as $\mathrm{Mn}, \mathrm{Ni}$ and $\mathrm{Zn}$ (Figure 6c, 6f and $6 \mathrm{~g}$ ). Meanwhile LFS material showed high efficiency to adsorb more $\mathrm{Pb}$ and $\mathrm{Cu}$ throughout the retention time (Fig. 6a and 6e). Biomass ash also displayed high efficiency to adsorb more $\mathrm{Cu}$ at day 20 of the operation. After 30 days of the treatment process and onwards, all toxic metals were completely removed by LFS except for As. The removal efficiency results for last day of remediation process indicated the capability of FA to remove greatly $\mathrm{Mn}, \mathrm{Fe}$ and $\mathrm{Ni}$, meanwhile LFS have high efficiency to remove $\mathrm{Pb}$ and $\mathrm{Mn}$. Fly ash can effectively remove $\mathrm{Mn}$ from the solution by precipitation due to the high $\mathrm{pH}$ (Belviso et al., 2014). According to Bhattacharya et al. (2008), the adsorbent is effectively removing more than $99 \%$ of $\mathrm{Fe}$ and its available sorption sites that influencing the time required to reach equilibrium level. The adsorbents tend to decrease the rate of adsorption which at equilibrium and achieved a limiting value (Irvan et al., 2013).

\section{Conclusion}

A chemical treatment process using industrial waste such as Slag (LFS), fly ash (FA) and biomass ash (BA) were applied for heavy metals contaminated acid mine drainage in continuous stir tank experiments. This work demonstrates that after 50 days of tank experiment, the $\mathrm{pH}$ of all AMD solution with different adsorbents was increased while the concentration of metals declined through the days. The continuous tank experiments with acid mine drainage showed removal efficiencies with order of $\mathrm{Mn}>\mathrm{Fe}>\mathrm{Ni}>\mathrm{Cu}>\mathrm{Pb}>\mathrm{Cd}>\mathrm{Zn}>$ As using fly ash were higher than using LFS and biomass, meanwhile LFS has high adsorption capacity to adsorb more $\mathrm{Pb}>\mathrm{Mn}>\mathrm{Fe}>\mathrm{Cu}>\mathrm{Cd}>\mathrm{Ni}>\mathrm{Zn}>\mathrm{As}$ suggesting that chemical treatment using LFS is more effective to remove this metals from polluted water. It is concluded that industrial wastes can be used as the best adsorbent because of the dual advantage of the high potential to neutralize $\mathrm{pH}$ in acidic phase and the advantage of the great adsorption capacity in removal of metal ions for improving water quality.

\section{Acknowledgment}

The authors would like to acknowledge the UKM for providing all the facilities and financial support for this research program for the remediation of acid mine drainage.

\section{Author's Contributions}

Nuur Hani Mohammed: Participated all experiment coordinated the data-analysis and contributed to the writing of the manuscript

Mustapha Atta: Coordinated the mouse work

Wan Zuhairi Wan Yaacub: Designed the research plan and organized the study

\section{Ethics}

The treatment processes are associated with the production of wastes, some of which are unavoidable, unrecyclable and hazardous. Such wastes require careful management to ensure adequate protection of humans and the environment. Thus, the wastes should be managed in a right way that secures an acceptable level of protection for human health and the environment, and affords to future generations at least the level of safety which is acceptable today.

\section{References}

Bhattacharya, A.K., T.K. Naiya, S.N. Mandal and S.K. Das, 2008. Adsorption, kinetics and equilibrium studies on removal of $\mathrm{Cr}(\mathrm{VI})$ from aqueous solutions using different low-cost adsorbents. Chem. Eng. J., 137: 529-541.

Belviso, C., F. Cavalcante, S. De Gennaro, A. Lettino and A. Palma et al., 2014. J. Environ. Manage., 1: 16-22.

Bernhard, D., 2014. Evolution of acid mine drainage formation in sulfidic mine tailings. Minerals J., 4: 621-641.

Cao, J., G. Zhang, Z. Mao, Z. Fang and C. Yang, 2008. Precipitation of valuable metals from bioleaching solution by biogenic sulfides. Minerals Eng., 22: 289-295.

Cooney, D.O., 1998. Adsorption Design for Wastewater Treatment. 1st Edn., CRC Press, ISBN-10: 1566703336, pp: 208.

Cullen, W.R. and K.J. Rheimer, 1989. Arsenic speciation in the environment. Chem, Rev., 89: 713-764.

Dybowska, A., M. Farago, J.E. Valsami and I. Thornton, 2006. Remediation strategies for historical mining and smelting sites.General Sci. Technol. J., 89: 71-138.

Fontana, M.G. and N.D. Greene, 1967. Corrosion engineering. 1st Edn., McGraw-Hill.

Ghanashyam, N. and J. Rona, 2013. Leachability of elements in alkaline and acidic coal fly ash samples during batch and column leaching tests. FUEL, 104: 758-770.

Gitari, M.W., L.F. Petrik, K. Etchebers, D.L. Key and E. Iwuoha et al., 2006. Treatment of acid mine drainage with fly ash: Removal of major contaminant and trace element. J. Environ. Sci. Health, 41: 1729-1747.

Hefa, C., H. Yuanan, L. Jian, X. Bin and Z. Jianfu, 2009. Geochemical processes controlling fate and transport 
of arsenic in Acid Mine Drainage (AMD) and natural systems. J. Hazardous Materials, 165: 13-26.

Hendricks, N.R., 2005. The application of high capacity ion exchange adsorbent material, synthesized from fly as hand acid mine drainage, for the removal of heavy and trace metals from secondary co-disposed process water. $\mathrm{PhD}$ Thesis University of the Western Cape.

Irvan, D., R.H. Siti and L.H. Mohd, 2013. Removal of iron (Fe ) from aqueous solutions using siliceous waste sorbent. Sustain. Environ. Res., 23: 41-48.

Kumar, V.R., M.J. Klink and D. Key, 2008. Neutralization of acid mine drainage using fly ash and strength development of the resulting solid residues. South Afr. J. Sci., 104: 317-324.

Kwong, Y.T.J., 1993. Prediction and Prevention of acid rock drainage from a geological and mineralogical perspective. Mine Environ. Neutral Drainage.

Michalik, M. and W. Wilczynska, 2012. Mineral and chemical composition of biomass ash. Eur. Mineralogical Conference, 1: 423-423.

Narottam, B., A. Shahreer and P. Carlos, 2015. Characterization of Ladle furnace slag and its utilization in steel making. SABIC Metal Technol.
Nunes, L.J.R., J.C.O. Matias and J.P.S. Catalao, 2016. Biomass combustion systems: A review on the physical and chemical properties of the ashes. Renewable Sustainable Energy Rev., 53: 235-242.

Rimstidt, J.D., J.A. Chermak and P.M. Gagen, 1994. Rates of reaction of galena, sphalerite, chalcopyrite and arsenopyrite with Fe(III) in Acidic Solutions. Environ. Geochemistry Sulfide Oxidation, 550: 2-13. DOI: 10.1021/bk-1994-0550.ch001

Rios, C.A, C.D. Williams and C.L. Roberts, 2008. Removal of heavy metals from Acid Mine Drainage (AMD) using coal fly ash, natural clinker and synthetic zeolites. J. Hazardous Materials, 156: 23-35.

Ritchie, Jambor, J.L. and Blowes, D., 1994. Sulfide Oxidation Mechanisms: Controls and Rates of Oxygen Transport. In: Short Course Handbook on Environmental Geochemistry of Sulfide Mine-Waste. Mineralogical Association of Canada, Edmonton.

Sadiq, M., 1997. Arsenic chemistry in soils: An overview of thermodynamic prediction and field observations. Water, Air, Soil Pollut., 93: 117-136.

Silva, A.M., E.C. Cunha, F.D. Reis and V.A. Leao, 2012. Treatment of high-manganese mine water with limestone and sodium carbonate. J. Cleaner Product., 29-30: 11-19. 